\title{
Review \\ Mediator-Related Symptoms and Anaphylaxis in Children with Mastocytosis
}

\author{
Knut Brockow ${ }^{1, *,+}\left(\mathbb{D}\right.$, Katarzyna Plata-Nazar ${ }^{2, *},+\left(\mathbb{D}\right.$, Magdalena Lange $^{3} \mathbb{D}$, Bogusław Nedoszytko ${ }^{3} \mathbb{D}$, \\ Marek Niedoszytko ${ }^{4}$ and Peter Valent ${ }^{5,6}$ (D)
}

1 Department of Dermatology and Allergology Biederstein, School of Medicine, Technical University of Munich, Biedersteiner Strasse 29, D-80802 Munich, Germany

2 Department of Paediatrics, Paediatric Gastroenterology, Allergology and Nutrition, Medical University of Gdańsk, 80803 Gdańsk, Poland

3 Department of Dermatology, Venereology and Allergology, Medical University of Gdańsk, 80210 Gdansk, Poland; m.lange@gumed.edu.pl (M.L.); bned@gumed.edu.pl (B.N.)

4 Department of Allergology, Medical University of Gdańsk, 80210 Gdansk, Poland; marek.niedoszytko@gumed.edu.pl

5 Department of Internal Medicine I, Division of Hematology \& Hemostaseology, Medical University of Vienna, 1090 Vienna, Austria; peter.valent@meduniwien.ac.at

6 Ludwig Boltzmann Institute for Hematology and Oncology, Medical University of Vienna, 1090 Vienna, Austria

* Correspondence: knut.brockow@tum.de (K.B.); katarzyna.plata-nazar@gumed.edu.pl (K.P.-N.); Tel.: +48-58-7640440(K.P.-N.); Fax: +48-58-7640445 (K.P.-N.)

+ These authors contributed equally to this work.

Citation: Brockow, K.; Plata-Nazar, K. Lange, M.; Nedoszytko, B.;

Niedoszytko, M.; Valent, P

Mediator-Related Symptoms and Anaphylaxis in Children with Mastocytosis. Int. J. Mol. Sci. 2021, 22, 2684. https://doi.org/10.3390/ ijms22052684

Academic Editor: Gianni Marone

Received: 31 January 2021

Accepted: 2 March 2021

Published: 7 March 2021

Publisher's Note: MDPI stays neutral with regard to jurisdictional claims in published maps and institutional affiliations.

Copyright: (c) 2021 by the authors. Licensee MDPI, Basel, Switzerland. This article is an open access article distributed under the terms and conditions of the Creative Commons Attribution (CC BY) license (https:// creativecommons.org/licenses/by/ $4.0 /)$.
Abstract: Mastocytosis is characterized by the pathological accumulation of mast cells (MC) in various organs. In these patients, MC may degranulate and thereby contribute to clinical symptoms, especially when a concomitant allergy is present. However, MC activation can not only be induced by high-affinity receptors for IgE, but also by anaphylatoxins, neuropeptides, IgG immune complexes, complement-components, drugs, products of bacteria or parasites, as well as physical factors such as heat, cold, vibration, stress, sun, or physical effort. Symptoms due to mediators released by activated MC may develop in adults suffering from systemic mastocytosis, but also evolve in children who usually have cutaneous mastocytosis (CM). Clinically, $\mathrm{CM}$ is otherwise characterized by typical brown, maculopapular skin lesions or mastocytoma associated with a positive Darier's sign. Pruritus and flushing are common and blistering may also be recorded, especially in diffuse CM (DCM). Pediatric patients with mastocytosis may also have gastrointestinal, respiratory, and neurologic complaints. Although anaphylaxis is not a typical finding, pediatric patients with massive skin involvement and high tryptase levels have a relatively high risk to develop anaphylaxis. This paper reviews MC mediator-related symptoms and anaphylaxis in children with mastocytosis, with special emphasis on risk factors, triggers, and management.

Keywords: mast cells; mastocytosis; mediator-related symptoms; anaphylaxis; children

\section{Introduction}

Mastocytosis is a heterogeneous group of disorders characterized by the pathological accumulation of mast cells (MCs) in one or more organs [1-3]. In a subset of patients, symptoms of MC activation are found [1-3]. Although mastocytosis can occur throughout life, there is a pronounced peak of incidence within the first two years of life [4]. Mastocytosis is rare, with a similar prevalence seen in different races. Overall, there is a slight predominance of boys in children and women among adults [5]. The disease may encompass only the skin (cutaneous mastocytosis, CM), or may involve internal organs such as bone marrow, liver, spleen, gastrointestinal tract, and lymph nodes (systemic mastocytosis, SM), with $(\mathrm{SM}+)$ or without (SM-) skin involvement [3,6-8]. In more advanced forms of disease, 
MC infiltration may lead to impairment or (sometimes even irreversible) damage of the affected organ systems [7,9-11]. CM is the most common form of mastocytosis in children and comprises over $90 \%$ of cases in this age group [8]. About $60-80 \%$ of pediatric patients may go into spontaneous remission in adolescence [2,5]. SM is infrequent in children and indicates a risk for persistence of the disease into adulthood [5]. Most children with SM have indolent $\mathrm{SM}$, whereas advanced pediatric SM is very rare $[1,5,12,13]$. Complaints of patients with pediatric mastocytosis, apart from cosmetic consequences of the skin lesions, are mostly on symptoms caused by mediators released from MCs. These symptoms may be mild, moderate, or rarely life-threatening. MC mediator-related events may present as sudden attacks, intermittently, or may be observed repeatedly during the course of disease. These symptoms can be recorded in children with CM and SM [5,14-16].

\section{Mediators Released from MCs}

MCs were described by Paul Ehrlich, Noble Prize winner and one of the grandmasters of modern immunology, who was born in 1854 in Strzelin near Wroclaw (now in Poland, Prussia in 1854) [17]. MCs contain granules packed with vasoactive and immunomodulatory mediators that can be visualized by metachromatic staining $[6,18]$. Different pathways may lead to MC activation and degranulation. One important signaling pathway is activated by high-affinity receptors for IgE. This activation pathway is particularly relevant to immediate type allergic reactions [19]. However, multiple other triggers of MC activation have been described, including certain cytokines, anaphylatoxins, neuropeptides, IgG immune complexes, complement, drugs, radiocontrast media, products of bacteria, or parasites [2]. Physical factors such as heat, cold, vibration, stress, sun, physical effort may also contribute to or induce MC activation and act as co-factors in allergic and anaphylactic reactions [20]. MCs contain two types of mediators-the first stored in the cytoplasmic granules (responsible for the early phase of allergic reaction) and the second synthesized during and after MC activation (responsible for the late phase reaction) [21]. Preformed mediators include histamine, tryptase, chymase, carboxypeptidase, and heparin. Mediators synthesized during MC activation are lipids, such as prostaglandin D2, leukotriene C4, platelet-activating factor, and cytokines, including interleukin-5 (IL-5), IL-6, transforming growth factor- $\beta$, or tumor necrosis factor $\alpha$ [21]. However, it should be mentioned that most of these cytokines have been detected in murine MCs rather than in human MCs. In human MCs, other MC-derived cytokines and chemokines may play a role in MCrelated functions and particularly in the mastocytosis context. These compounds include, among others, vascular endothelial growth factor (VEGF), IL-8, monocyte chemoattractant protein-1 (MCP-1), and oncostatin-M [22-25].

Mediators released from MCs evoke vascular, gastrointestinal, bronchial smooth muscle, and endothelial cell responses leading to vasodilatation and microvascular permeability, stimulation of mucus glands, and afferent nerve endings [26]. Histamine is one of the most important mediators released by degranulating MCs [27,28]. Histamine can cause symptoms in the skin (pruritus, urticaria, reddening/flushing, angioedema), in the respiratory system (runny nose, sneezing, coughing, wheezing, bronchospasm), in the gastrointestinal system (abdominal cramps, diarrhea, vomiting, gastric hypersecretion), and the circulatory system (tachycardia, hypotension, anaphylactic shock) [29]. Tryptase is the most common, sensitive, and relatively specific mediator of MC activation and has found application in laboratory diagnostics. Heparin-a polysaccharide, inhibits the blood clotting at a stage when prothrombin is converted into thrombin and thus prevents the formation of blood clots in the blood vessels. It is an anticoagulant and intensifies bleeding tendency. Prostaglandin $\mathrm{D}_{2}\left(\mathrm{PGD}_{2}\right)$ is the major eicosanoid product of MCs and is released in large quantities during anaphylaxis and asthma attacks. Patients suffering from mastocytosis produce excessive amounts of $\mathrm{PGD}_{2}$, which causes flushing, vasodilation, hypotension, and syncopal episodes. $\mathrm{PGD}_{2}$ can also induce increased motility of the gastrointestinal tract, manifested by diarrhea [29]. Leukotriene C4 (LTC4) plays a role in inflammation, immunological functions, and maintaining biological homeostasis. LTC4 induces mucus 
secretion in airways and long-lasting hypotension, reduces myocardial contractility and coronary blood flow, and interferes with the motility function of the gastrointestinal tract (abdominal pain, diarrhea) [29]. Platelet-activating factor (PAF) causes bronchoconstriction and increases the permeability of blood vessels. MC-derived cytokines may also attract other inflammatory cells from the circulation, such as neutrophils, eosinophils, and T lymphocytes, to extend the local inflammatory response [30-33]. Nevertheless, the assessment of the exact role of all these mediators in the pathogenesis of mastocytosis requires further studies.

\section{Mediator-Related Symptoms in Children with Mastocytosis}

\subsection{Cutaneous Symptoms}

In most children, mastocytosis infiltrates are limited to the skin and the diagnosis is thus CM. In these patients, CM often presents as maculopapular brown skin lesions (MPCM), but may also present as erythroderma and pachyderma typical for diffuse cutaneous mastocytosis (DCM) or up to four nodular or plague lesions termed mastocytoma [8]. Regardless of the subform, CM may be associated with MC mediator-related symptoms in the skin such as pruritus, flushing, and blistering [34-36]. Generally, the probability for having these symptoms is more likely in patients with indurated skin lesions containing packed accumulations of MCs typically seen in DCM. The Darier's signs is pathognomonic for mastocytosis patients with skin lesions, including $\mathrm{CM}$, and presents as erythema and edema, which is observed within a few minutes after mechanical irritation of lesional skin [8]. The Darier's sign is present in up to $90 \%$ of all patients with mastocytosis [5]. However, absence of the Darier's sign does not exclude the diagnosis of mastocytosis $[1,15]$. The Darier's sign should be elicited gently in case of large mastocytoma, as it may result in flushing and hypotension [8,37]. Pruritus is a very common skin symptom and occurs in at least half of the children with mastocytosis $(46-79 \%)[5,14,15,36]$. Flushing is also relatively common in childhood CM (20-65\%) $[1,5,36]$. In some of the patients, flushing precedes the development of anaphylaxis [16,38]. Blisters occur preferentially in children under 2-3 years of age, often in the context of DCM. Overall, blistering is reported in about $25-35 \%$ of children with mastocytosis $[5,15,36,39]$.

\subsection{Extracutaneous Systemic Symptoms}

Although MC mediator-related symptoms in pediatric mastocytosis are typically cutaneous, children may also suffer from gastrointestinal (up to $40 \%$ of children), respiratory $(13 \%)$, and neurologic $(6-18 \%)$ symptoms $[5,15,36,39]$. Gastrointestinal symptoms comprise abdominal pain, cramps, bloating, diarrhea, nausea, and vomiting $[1,5,38,39]$. Histamine (and other mediators) increases gastric acid secretion, leads to hyperacidity, and may induce gastroduodenal ulcer disease. Patients with moderate or severe symptoms should be referred to a gastroenterologist and further tests, including endoscopy, should be considered. Respiratory symptoms caused by MC mediators are not commonly seen in children with mastocytosis $(<13 \%)$ [15]. These symptoms may include nasal pruritus, rhinorrhea, bronchoconstriction, wheezing, stridor, and cough $[1,28]$. Neurologic symptoms reported in patients with pediatric mastocytosis include, among others, aggressive behavior, anxiety, depression, and loss of concentration [34,40]. Autistic behavior has also been described in children with mastocytosis [41]. Cardiovascular symptoms, including tachycardia, hypotension, shock, or collapse are very rare $[14,36]$. These symptoms occur mainly in children with extensive skin lesions and elevated serum tryptase level [14,15,42]. Similarly, musculoskeletal symptoms such as pain, osteopenia, osteoporosis, and pathologic fractures are rarely found in children with mastocytosis (6-13\%) [5,39]. Constitutional symptoms such as fever, fatigue, or weight loss are also rare in children. All these symptoms occur in SM rather than in patients with CM $[1,4,37]$. 


\subsection{Anaphylaxis}

In children with mastocytosis, the reported percentage of anaphylaxis ranges between $0 \%$ and $9 \%$ (Table 1) [43,44]. Thus, the prevalence of anaphylaxis described in childhood mastocytosis is higher than the frequency reported in the general pediatric population $(0.02-0.05 \%)$ [45]. On the other hand, anaphylaxis in childhood patients with mastocytosis is less frequently recorded compared to anaphylaxis in adults with mastocytosis $[43,46]$.

Table 1. Frequency of anaphylaxis in children with mastocytosis in the literature.

\begin{tabular}{ccccc}
\hline Study $^{*}$ & Year & No & Frequency & Elicitors \\
\hline Gonzales [46] & 2007 & 47 & $3(6.4 \%)$ & Food, idiopathic \\
\hline Brockow [43] & 2008 & 46 & $4(9 \%)$ & Food, vaccination, cold water, idiopathic \\
\hline Alvarez-Twose [14] & 2012 & 111 & $4(3.6 \%)$ & Heat, skin rubbing, fever \\
\hline Lange [36] & 2013 & 101 & $7(7 \%)$ & Clindamycin, ketamine, gadolinium contrast, stress, idiopathic \\
\hline Barnes [15] & 2014 & 67 & $1(1,5 \%)$ & NA \\
\hline Matito [47] & 2015 & 48 & $1(2.0 \%)$ & Ketamine, idiopathic \\
\hline Lange [39] & 2017 & 102 & $2(2 \%)$ & NA \\
\hline Heinze [44] & 2017 & 43 & $0(0 \%)$ & $\mathbf{2 2 ~ ( 3 . 9 \% )}$ \\
\hline Studies combined & & $\mathbf{5 6 5}$ & * First authors; NA = not available.
\end{tabular}

\subsection{Triggering Factors of Mediator-Related Symptoms and Anaphylaxis}

Systemic symptoms induced by MC mediators can occur spontaneously or are provoked by certain stimuli, such as hymenoptera insect stings, aspirin allergen exposure, contrast media, surgery or endoscopy, and infections (bacteria, viruses, others).

The most prominent trigger of anaphylaxis in adults with mastocytosis is insect venom $[43,48,49]$, whereas surprisingly in children with mastocytosis, hymenoptera stings are not a frequent trigger and there is no evidence for an increased risk in this patient group (Table 1) [34,50]. Correspondingly, in the pediatric populations with insect sting anaphylaxis presenting in the allergy clinic for allergy workup and in unselected patients presenting for acute treatment of anaphylaxis in an emergency department, the diagnosis of mastocytosis is very rare [50,51]. In one study of children with MPCM, hymenoptera stings occurred in $51 \%$ of 43 children, with no reports of anaphylaxis [44].

Foods and drugs have also been reported by patients as potential triggers of anaphylaxis in adults as well as in children with mastocytosis [34,50,52-54]. It has been described that children with mastocytosis may have a higher risk to develop adverse reactions to vaccines than healthy controls $[55,56]$. However, with a few exceptions, no anaphylaxis was reported after vaccination in childhood patients with mastocytosis $[43,55,56]$. Anesthesia may rarely be associated with MC mediator release [54]. One study reported perioperative anaphylaxis in one out of 50 anesthetic procedures in 48 children with mastocytosis during general anesthesia for major surgery [47]. The child who had developed an anaphylactic reaction, was able to tolerate the same anesthetic procedure at a later time. In another study, no serious adverse events occurred in children with mastocytosis undergoing surgical procedures [57].

Physical stimuli, such as jumping into cold water has been reported anecdotally as a trigger for anaphylaxis [36,43]. If no potential trigger is found, idiopathic anaphylaxis is diagnosed. Idiopathic anaphylaxis has also been reported in a minority of adults with anaphylaxis [58], but is the primary etiology reported in pediatric mastocytosis [14,34]. It has to be considered, however, that idiopathic anaphylaxis is more a provisional than a final diagnosis regarding the lack of identified trigger factors and before it is diagnosed, all potential known triggers which can be tested should be ruled out. It may well be that trigger factors do exist, but have not been tested for or yet described. 


\subsection{Risk Factors for Anaphylaxis in Children with Mastocytosis}

Anaphylaxis can also occur in a child with mastocytosis and is difficult to predict reliably $[36,59]$. However, important risk factors have been identified for anaphylaxis in children (Table 2) [60,61]. In one study, the extent and density of skin lesions and higher serum tryptase values have been identified as risk factors for anaphylaxis in children with mastocytosis [43]. This is in agreement with another study, where the maximum number of maculopapular cutaneous mastocytosis lesions and the skin symptoms, such as itching, blistering, and flushing were statistically significant predictors of occurrence of systemic symptoms in a multivariate linear regression analysis [15]. Furthermore, DCM, the most extensive form of cutaneous mastocytosis, which is associated with high serum tryptase values, has been reported as a risk factor for more severe anaphylaxis [14]. A study with 111 children suffering from mastocytosis with skin involvement (mostly CM) looked for predictors for severe MC activation episodes, of which most appear to fulfil the definition of anaphylaxis [14]. In this study all 12 children with severe symptoms who required hospitalization had extensive cutaneous disease, more than $90 \%$ of the body surface area involved, and significantly higher levels of serum tryptase compared with the other children without such severe skin involvement and MC burden. Nine out of nine children (100\%) with DCM had severe MC mediator-induced symptoms requiring hospitalization. Only three out of 102 children with nodular or maculopapular cutaneous mastocytosis required hospitalization because of the severity of mediator-related symptoms. Another analysis of this study revealed that blistering episodes are a risk factor for acute severe reactions requiring hospitalization [16]. Thus, children with severe skin involvement in CM, high serum tryptase levels, and DCM are at higher risk to develop anaphylaxis, particularly during blistering episodes, whereas the risk in the other patient groups seems to be low and might not be substantially increased as compared to the general population (Table 2) $[14,15,34,43,46]$. This is also substantiated by a higher prevalence of anaphylaxis in those studies with children more affected by skin involvement and serum tryptase levels as compared to those with uncomplicated limited maculopapular cutaneous mastocytosis (urticaria pigmentosa) $[14,16,45]$.

Table 2. Risk factors for anaphylaxis in children with mastocytosis (adapted from [60]).

\begin{tabular}{crr}
\hline Criterium & Risk Factor Outcome & Study \\
\hline Extent and density of skin lesions & Anaphylaxis in those with extent $>45 \%$ and density $>15 \%$ & Brockow et al. [43] \\
\hline Serum tryptase & Significantly elevated in patients with anaphylaxis & Brockow et al. [43] \\
\hline Skin involvement & Correlation with severity & Alvarez-Twose et al. [14] \\
\hline Blistering & $>90 \%$ : risk factor for hospitalization ${ }^{*}$ & Alvarez-Twose et al. [14] \\
\hline Diffuse cutaneous mastocytosis & Risk factor for hospitalization * & Brockow et al. [16] \\
\hline & Risk factor for hospitalization * & Alvarez-Twose et al. [14] \\
\hline
\end{tabular}

\subsection{Hereditary Alpha-Tryptasemia as Risk Factor for Mediator-Related Symptoms and Anaphylaxis}

Recently, hereditary alpha-tryptasemia $(\mathrm{H} \alpha \mathrm{T})$ has been described, a genetic trait with duplicated TPSAB1 germline copy numbers leading to elevated basal serum tryptase [62-64], but also to MC mediator-related symptoms. It can be found in about $5 \%$ of unselected healthy individuals [63-67]. The prevalence of certain symptoms related to MC activation has been described to be higher in $\mathrm{H} \alpha \mathrm{T}$ carriers than in the general population, with urticaria/angioedema in 51\%, skin flushing/pruritus in 32-55\%, and irritable bowel syndrome or food intolerance in $28-49 \%$ of patients [59,64]. The presence of $\mathrm{H} \alpha \mathrm{T}$ was identified as a heritable genetic risk factor for severe grade IV hymenoptera venom anaphylaxis, for idiopathic anaphylaxis and for SM in comparison to controls [67]. The prevalence of $\mathrm{H} \alpha \mathrm{T}$ was similar in patients with hymenoptera venom allergy with and without masto- 
cytosis, however their clinical reactions were more severe. In a study assessing TPSAB1 germline copy number variants in 180 mastocytosis patients, 180 sex-matched control subjects, 720 patients with other myeloid neoplasms, and 61 additional mastocytosis patients of an independent validation cohort, $\alpha$-tryptase encoding TPSAB1 copy number gains corresponding to $\mathrm{H} \alpha \mathrm{T}$ were identified in $17.2 \%$ of mastocytosis patients as compared to only $4.4 \%$ of the control population $(p<0.001)$ [65]. This pronounced difference indicates a possible pathogenic role of TPSAB1 copy number gains in the evolution of mastocytosis. Patients with $\mathrm{H} \alpha \mathrm{T}$ had highly significantly increased tryptase levels as compared to patients without $\mathrm{H} \alpha \mathrm{T}$, which was independent of the mast cell burden. In patients with mastocytosis, hymenoptera venom hypersensitivity reactions and severe anaphylaxis were much more frequent in patients with $\mathrm{H} \alpha \mathrm{T}$ as compared to $\mathrm{H} \alpha \mathrm{T}$-negative mastocytosis patients. The study concluded that $\mathrm{H} \alpha \mathrm{T}$ is an important biomarker for a predisposition to develop severe anaphylaxis in mastocytosis (Figure 1)

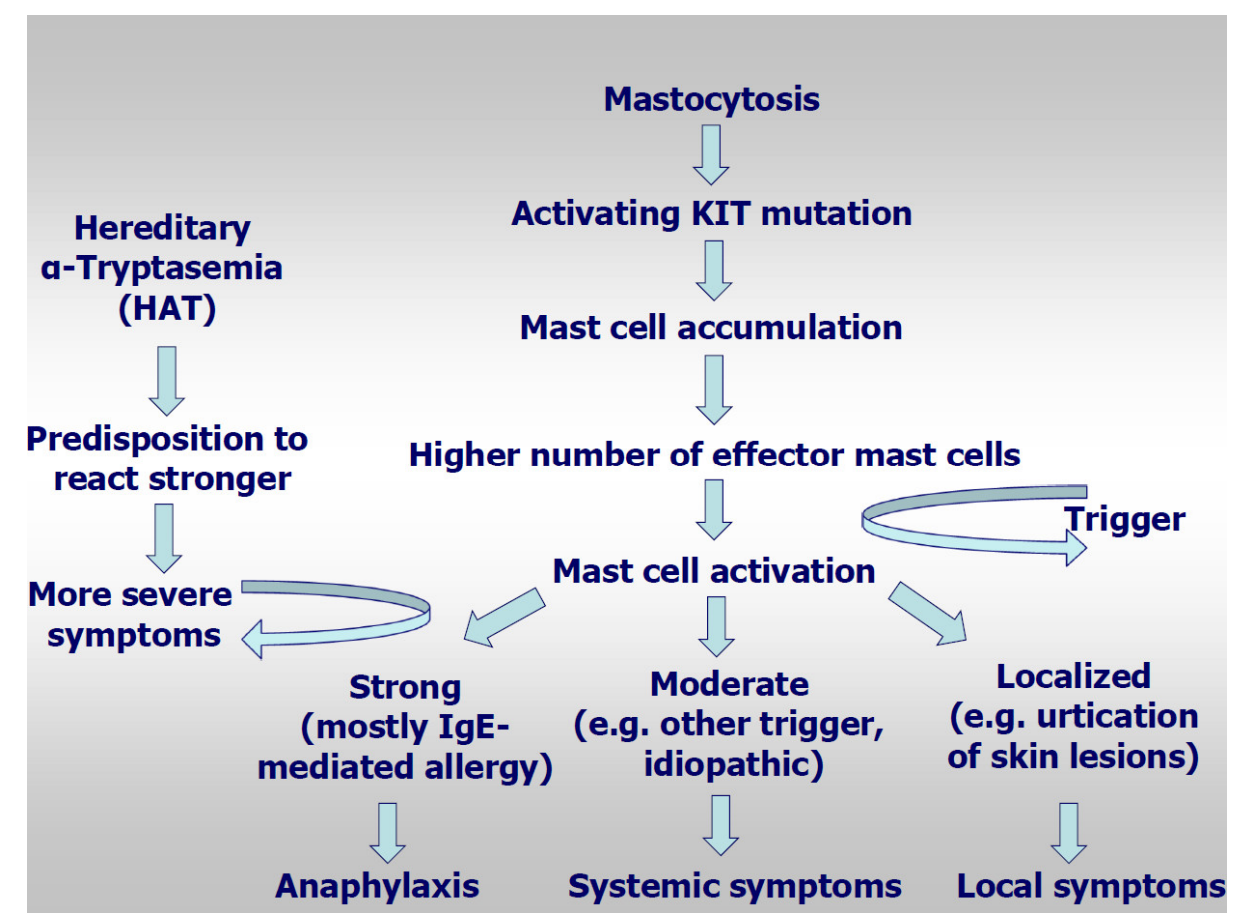

Figure 1. Model for pathogenesis of anaphylaxis in mastocytosis.

In fact, we speculate that an increased amount of tryptase may also lead to an increased load of other mediators (per mast cell) that are rapidly released by these cells through an anaphylactic event. An alternative explanation, recently been proposed by Le et al. [66], is that hetero-tetramers of tryptase, composed of $2 \alpha$ - and $2 \beta$-tryptase protomers ( $\alpha / \beta$-tryptase), activate protease-activated receptor- 2 on smooth muscle, neurons, and endothelium and increase mast cell susceptibility to vibration-triggered degranulation by cleaving the $\alpha$ subunit of the EGF-like module-containing EMR2. The severity of the anaphylaxis in HAT may be caused by the increased vascular permeability which may lead to rapid hypotension caused by systemic allergic reaction. The study by Lyons et al. showed that tryptase hetero-tetramers selectively cleave PAR-2 (protease-activates receptor 2) on human vascular endothelial cell monolayers which increases vascular permeability [67].

Sabato et al. diagnosed $\mathrm{H} \alpha \mathrm{T}$ in three of four family members suffering from recurrent episodes of abdominal cramping and diarrhea who were diagnosed as MC activation syndrome (MCAS) [68]. These studies so far included adult patients, whereas little is known about symptoms and the severity of symptoms in childhood carriers of $\mathrm{H} \alpha \mathrm{T}$ in $\mathrm{CM}$. In the pediatric population, gastrointestinal symptoms, urticaria, and hymenoptera venom allergy are rare. Mean serum tryptase, measured in 131 children aged 3 months to 18 years 
and hospitalized due to temporary self-resolving symptoms, was low $(2.8 \pm 2.2 \mathrm{ng} / \mathrm{mL})$ with an upper reference limit of $7.2 \mathrm{ng} / \mathrm{mL}$ [69]. Further studies are required to indicate, if analysis of TPSAB1 copy numbers may become a part of the standard examination performed in children with anaphylaxis and MC activation syndrome. The diagnosis of $\mathrm{H} \alpha \mathrm{T}$ should be considered when basal tryptase level is $\geq 8-10 \mathrm{ng} / \mathrm{mL}$ [63].

\section{Diagnostic Testing}

A step-wise approach in children with suspected mastocytosis is recommended [2,70]. A thorough medical history collected from the patient includes the date of the first symptoms, duration of the disease, manifestations, localization, number of skin lesions (increase/decrease), their morphology, variability, factors provoking mediator release, related acute clinical symptoms, accompanying symptoms, and family history (mastocytosis in the family). A physical examination of the child should assess the physical development (weight, length), should be carried out with special attention to the inspection of the entire skin surface, palpation of all groups of lymph nodes (unexplained lymphadenopathy?), and abdomen examination (hepatosplenomegaly?) [40]. In children with skin lesions, histopathological examination of the skin may be indicated to establish the final diagnosis [8].

In all children, baseline serum tryptase levels should be obtained because a very high serum tryptase level (over $100 \mathrm{ng} / \mathrm{mL}$ ) may be indicative of a high MC burden and/or the presence of SM [7,70-73]. Serum tryptase levels are usually within a normal range or slightly elevated in CM whereas tryptase levels are clearly elevated in most patients with SM and DCM $[10,36,42,74,75]$. Interestingly, patients with severe MC mediatorrelated symptoms or MCAS do not always have an elevated baseline serum tryptase level. Moreover, worsening of symptoms does not always correlate with an increase of tryptase level $[4,35]$. In children with mastocytosis, baseline level should be determined at least 24-48 $\mathrm{h}$ after the complete resolution of severe mediator-related symptoms [7,70]. In those children with elevated tryptase levels above $10 \mu \mathrm{g} / 1$ and severe MC-mediated symptoms, it is prudent to determine extra copies of the alpha tryptase gene (TPSAB1), if the test is available, to better understand the genetic basis of these symptoms.

Other recommended laboratory tests include a complete blood count with white blood cells, differential counts, and liver function tests [7,40]; however, abnormalities in blood counts and serum chemistry parameters are uncommon in childhood CM [34]. If hepatosplenomegaly is present, children should have an abdominal ultrasound or computer tomography. Organomegaly is a strong indicator of systemic disease [9]. Therefore, in children with mastocytosis associated with organomegaly, after excluding other causes, a detailed hematology work-up and the determination of KIT D816V mutation in peripheral blood $(\mathrm{PB})$ has been recommended $[13,70,72,73]$. Bone marrow examination including histopathology, cytology, and flow cytometry is considered in children with KIT D816V mutation in peripheral blood (PB) and/or with suspected advanced SM [4,12,13,75].

Children with mastocytosis should be followed-up regularly, also when they reach adulthood.

\section{Treatment}

Children with mastocytosis may require a multidisciplinary approach and should best be diagnosed and followed-up by centers with experience in managing the disease. As causal drug therapy is not available, mainly symptomatic treatment is recommended. Education of patients and their family members form the basis of mastocytosis management. Patients and parents should be alerted about possible triggering factors (e.g., physical factors, alcohol, infections, certain drugs, stress) and risk situations (e.g., hymenoptera sting, general anesthesia) that may potentially induce mediator-related symptoms. Nevertheless, avoidance of all agents in a long list of all potential triggers reported in the literature is not an appropriate approach. Rather, the patients and parents have to learn to avoid classical triggers and to strictly avoid all additional triggers against which the childhood patient did react in the past. 


\subsection{Topical Therapy of Skin Symptoms}

Local skin care with emollients may be applied in children with dry skin to prevent itching and scratching. Emollients decrease trans-epidermal water loss, moisture the skin, and seal the epidermal barrier which leads to the reduction of pruritus and decreases the sensitivity to physical stimuli [76]. Disodium cromoglycate at a concentration of $0.21 \%$ to $4 \%$ cream may be used to reduce pruritus $[77,78]$. Topical steroids against blistering should be used cautiously in children, and should only be applied in short-term therapy and for limited skin areas, because of numerous side effects of this therapy, particularly the risk of skin atrophy and adrenal suppression [79]. In infants, mild or medium potency corticosteroids are usually effective. Therapy with mometasone furoate $0.1 \%$ cream applied once daily to areas prone to the development of blistering in a neonate with DCM resulted in essential improvement [79]. The highly potent corticosteroid clobetasol propionate under occlusion has been used for solitary mastocytoma associated with recurrent blistering and pruritus, but may lead to skin atrophy [80]. Asymptomatic mastocytomas regress spontaneously and for this reason, local therapy is not necessary [81]. Mastocytoma associated with flushing or hypotension after mechanical irritation may be treated by surgical excision [80]. Therapy with topical antibiotics such as mupirocine or fucidic acid is recommended in children with denuded skin areas to prevent skin infections, particularly in those with blistering and DCM [34]. Another therapeutic option is pimecrolimus, a calcineurin inhibitor that has shown effects in children with symptomatic CM [82,83]. In particular, effective and safe therapy of MPCM and mastocytoma with $1 \%$ pimecrolimus cream applied twice daily on skin lesions was reported [82].

It has also been shown that narrow-band UVB (NB-UVB), as well as PUVA, reduces pruritus, and relieves skin symptoms in adults with both CM and ISM [84]. Also, in very selected children with extensive skin lesions and/or severe MC mediator-related symptoms unresponsive to antimediator therapy, phototherapy may be considered $[4,77,85]$. However, generally phototherapy and photochemotherapy PUVA (UVA in combination with psoralen) are not recommended in pediatric patients with mastocytosis. First, the tendency toward spontaneous regression of skin lesions around puberty is observed in a majority of children. Second, the overall period of symptom reduction is relatively short. Furthermore, little is known about the long-term safety of phototherapy in children $[86,87]$. PUVA therapy is associated with the risk of skin cancers (squamous skin carcinoma and melanoma), cataracts, and hepatotoxicity (psoralen-induced). Therefore, a very critical riskbenefit analysis should precede the decision of whether to apply any form of phototherapy in a child with CM.

\subsection{Systemic Therapy of MC Mediator-Induced Symptoms}

Oral antihistamines are the mainstay of anti-mediator therapy in pediatric mastocytosis. In symptomatic patients, first-line treatment is based on second-generation antihistamines, which block $\mathrm{H}_{1}$ receptors (cetirizine, desloratadine, fexofenadine, levocetirizine, loratadine and rupatadine, bilastine). They are applied to reduce itching and flushing, as well as general symptoms occurring as the result of the release of MC mediators. Age-appropriate doses are usually recommended, but sometimes it is necessary to administer up to four times the basic dose for age. First-generation antihistamines (chlorpheniramine, diphenhydramine, hydroxyzine, ketotifen, azelastine) are less commonly used due to their sedative effect; however, they are more effective in children with severe pruritus $[2,37,86,88-90]$. Antihistamines that block the $\mathrm{H}_{2}$ receptor are often used to alleviate gastrointestinal ailments, but currently for gastrointestinal symptoms, proton pump inhibitors and/or oral cromolyn sodium are applied with equal frequency $[2,37,88,91]$.

In case of blistering or systemic symptoms unresponsive to $\mathrm{H}_{1}$-antihistamines, cromolyn sodium, and proton pump inhibitors, leukotriene antagonists may be offered. Oral steroids are very effective, but should only be taken for a short term [34]. Long-term use may cause numerous side effects, some of which (like skin changes, hypertension, obesity, osteoporosis, osteonecrosis) may be irreversible [86]. 
In the rare pediatric cases with osteopenia and osteoporosis vitamin D3 preparations, calcium preparations, and bisphosphonates are recommended [2,3].

\subsection{Management of Anaphylaxis}

In children with mastocytosis, acute management depends on the severity of the reaction. The first-line medication is adrenaline (epinephrine), administered at a dose of $0.01 \mathrm{mg} / \mathrm{kg}$ in children. In Germany a prefilled autoinjectors are available with a dose of $0.15 \mathrm{mg}$ for children from $7.5-15 \mathrm{~kg}$ up to $25-30 \mathrm{~kg}$, depending on the license of the autoinjector [92]. Adrenaline should be administered intramuscularly and, if necessary, can be repeated every 5 to $15 \mathrm{~min}$ [61]. Supporting measures for cardiovascular or respiratory reactions are high-flow oxygen, positioning the patient (e.g., Trendelenburg position with the lower extremities elevated for hypotension), volume replacement as well as inhaled adrenaline or beta-agonists (e.g., salbutamol). For cutaneous or gastrointestinal reactions, $\mathrm{H}_{1}$ and $\mathrm{H}_{2}$ antihistamines +/- steroids and monitoring are normally sufficient. After stabilization, blood chemistry parameters, blood counts, and a serum tryptase level should be determined in all patients. A massive event-related increase in tryptase may lead to the diagnosis of an MCAS.

Emergency preparedness is important in those children and in those situations with higher risk for anaphylaxis. Thus, mastocytosis children with a huge burden of MC in the skin ( $>45 \%$ of skin surface and/or a maximum density of lesional skin in relation to non-involved skin of $>15 \%$ ), those with high serum tryptase levels ( $>20 \mathrm{ng} / \mathrm{mL}$ ), and cases with diffuse $\mathrm{CM}$ are at high risk for anaphylaxis (Table 2). Acute blistering episodes indicate a temporarily increased releasability of MCs and should be monitored carefully, and in the case of complications, the patient should be hospitalized. High-risk patients and family members should receive a prescription of a self-injectable adrenaline autoinjector and should carry it at all times. In children with less extensive mastocytosis and without a previous episode of anaphylaxis or individual risk factors (e.g., systemic peanut allergy) this is not required, because for those children the risk of anaphylaxis is low. Emergency kits for self-application may also contain an $\mathrm{H}_{1}$ antihistamine (e.g., dimethindene or cetirizine) and a corticosteroid (e.g., betamethasone) [92]. It is not sufficient to prescribe an emergency kit without appropriate instruction on how to recognize anaphylaxis and on how to use the emergency medication, best with an adrenaline injector trainer available from the producers, or even better after a structured anaphylaxis educational program [93]. A mastocytosis passport listing information on acute treatment, prescribed emergency medication, and drugs to avoid or to be given under medical supervision is very helpful for the patient.

Vaccination and anesthesia can be performed in children with mastocytosis. In those patients, precautions may be taken and emergency preparedness should be ensured [47]. The occurrence of reactions to vaccines in childhood mastocytosis has been predominantly reported after a hexavalent vaccine administration and injection of single vaccines has been suggested in children with diffuse cutaneous mastocytosis $[55,56]$. If this is necessary and appears unclear considering the mild severity of the reactions reported so far, however, administration of the first dose of vaccine to children with mastocytosis in a controlled clinical setting with monitoring of the patients for a prolonged observation interval (e.g., 1-2 h after injection or overnight in case moderate or severe reactions occur) is advisable. Although there is some disagreement on whether to recommend premedication with prophylactic anti-mediator-type therapy in every patient with mastocytosis before anesthesia it is advisable to recommend such prophylaxis at least in those with an unknown or a high risk to develop anaphylaxis [54]. Most pre-medications include an $\mathrm{H}_{1-}$ and $\mathrm{H}_{2}$-antihistamine and corticosteroids. Although premedication may not be needed in all children with mastocytosis, we recommend to consider in all cases and to administer in all with previously documented anaphylaxis. It is cautious to consider choosing those anesthetic drugs with low capacity to elicit MC degranulation as well as to use drugs with known tolerance by the individual child. Thus, a meticulous preparation and understand- 
ing of anesthetic implications are advised. It may also be important to reduce stress and anxiety, sometimes by the use of benzodiazepines, and to avoid temperature changes and mechanical stimulation for the patient [57]. Finally, it is important to inform the vaccination team and anesthesia team about the presence of a mast cell disease and, if known, the presence of a concomitant allergy.

Recently, omalizumab has been proposed for mastocytosis patients to treat severe mediator-related symptoms and to prevent anaphylaxis [3,94-104]. The drug was indeed found to be effective in the prevention of recurrent episodes of idiopathic anaphylaxis in adults with mastocytosis [94-104], but has to be licensed for use only in children over 12 years of age. The results of the XOLMA study has shown that omalizumab was safe and improved mastocytosis symptoms like diarrhea, dizziness, flush, and anaphylactic reactions [103]. First long-term follow-ups are available with improvement of clinical symptoms in two patients with SM and recurrent anaphylaxis over an observation period of 12 years [102]. Several case reports have suggested the usefulness of omalizumab in SM [95] and CM in adults [96], but also in adolescents [97], and children [98]. Omalizumab efficacy is not only restricted to allergic responses, but also abrogates non-allergic chronic spontaneous urticaria. It is believed that this effect is related to the downregulation of FceRI receptors on basophils and mast cells, however, its detailed mechanism of action is not currently understood [105]. On the other hand, most anaphylactic reactions in patients with mastocytosis and/or MCAS can now be explained by (often occult forms of an) IgEdependent allergy. Although the evidence is based only on uncontrolled observations in a small number of patients, this drug is likely to be effective in the prevention of recurrent anaphylaxis in children with or without mastocytosis [100]. Indeed, omalizumab has been described to prevent recurrent anaphylaxis attacks in a child with increased basal serum tryptase levels without mastocytosis [101]. The first approach, however, may be to administer high doses of anti-mediator type therapy (H1- and H2-antihistamines, cromoglycate, montelukast) and to study efficacy and tolerability of these drugs before offering omalizumab, which usually works in most patients (authors' personal experience).

Author Contributions: Writing-original draft preparation, K.B. and K.P.-N.; writing-review and editing, K.B., K.P.-N., M.L., B.N., M.N., P.V. All authors have read and agreed to the published version of the manuscript.

Funding: This project was supported by the Polish Ministry of Science and Higher Educationgrants: no ST 02-0066/07/253, no ST 02-0060/07. P.V. was supported by Austria Science Funds (FWF) Grants P32470-B and F4704-B20.

Conflicts of Interest: The authors declare no conflict of interest.

\section{References}

1. Castells, M.; Metcalfe, D.D.; Escribano, L. Diagnosis and treatment of cutaneous mastocytosis in children: Practical recommendations. Am. J. Clin. Dermatol. 2011, 12, 259-270. [CrossRef] [PubMed]

2. Broesby-Olsen, S.; Dybedal, I.; Gülen, T.; Kristensen, T.K.; Møller, M.B.; Ackermann, L.; Sääf, M.; Karlsson, M.A.; Agertoft, L.; Brixen, K.; et al. Multidisciplinary Management of Mastocytosis: Nordic Expert Group Consensus. Acta Derm. Venereol. 2016, 96, 602-612. [CrossRef] [PubMed]

3. Valent, P.; Akin, C.; Hartmann, K.; Nilsson, G.; Reite, A.; Hermine, O.; Sotlar, K.; Sperr, W.R.; Escribano, L.; George, T.I.; et al. Advances in the Classification and Treatment of Mastocytosis: Current Status and Outlook toward the Future. Cancer Res. 2017, 77, 1261-1270. [CrossRef]

4. Hussain, S.H. Pediatric mastocytosis. Curr. Opin. Pediatr. 2020, 32, 531-538. [CrossRef] [PubMed]

5. Méni, C.; Bruneau, J.; Georgin-Lavialle, S.; Le Saché de Peufeilhoux, L.; Damaj, G.; Hadj-Rabia, S.; Fraitag, S.; Dubreuil, P.; Hermine, O.; Bodemer, C. Paediatric mastocytosis: A systematic review of 1747 cases. Br. J. Dermatol. 2015, 172, 642-651. [CrossRef] [PubMed]

6. Valent, P.; Akin, C.; Hartmann, K.; Nilsson, G.; Reiter, A.; Hermine, O.; Sotlar, K.; Sperr, W.R.; Escribano, L.; George, T.I.; et al. Mast cells as a unique hematopoietic lineage and cell system: From Paul Ehrlich's visions to precision medicine concepts. Theranostics 2020, 10, 10743-10768. [CrossRef]

7. Valent, P.; Akin, C.; Gleixner, K.V.; Sperr, W.R.; Reiter, A.; Arock, M.; Triggiani, M. Multidisciplinary Challenges in Mastocytosis and How to Address with Personalized Medicine Approaches. Int. J. Mol. Sci. 2019, 20, 2976. [CrossRef] 
8. Hartmann, K.; Escribano, L.; Grattan, C.; Brockow, K.; Carter, M.C.; Alvarez-Twose, I.; Matito, A.; Broesby-Olsen, S.; Siebenhaar, F.; Lange, M.; et al. Cutaneous manifestations in patients with mastocytosis: Consensus report of the European Competence Network on Mastocytosis; the American Academy of Allergy, Asthma \&; Immunology; and the European Academy of Allergology and Clinical Immunology. J. Allergy Clin. Immunol. 2016, 137, 35-45.

9. Valent, P.; Horny, H.P.; Escribano, L.; Longley, B.J.; Li, C.Y.; Schwartz, L.B.; Marone, G.; Nuñez, R.; Akin, C.; Sotlar, K.; et al. Diagnostic criteria and classification of mastocytosis: A consensus proposal. Leuk Res. 2001, 25, 603-625. [CrossRef]

10. Valent, P.; Akin, C.; Metcalfe, D.D. Mastocytosis: 2016 updated WHO classification and novel emerging treatment concepts. Blood 2017, 129, 1420-1427. [CrossRef]

11. Arber, D.A.; Orazi, A.; Hasserjian, R.; Thiele, J.; Borowitz, M.J.; Le Beau, M.M.; Bloomfield, C.D.; Cazzola, M.; Vardiman, J.W. The 2016 revision to the World Health Organization classification of myeloid neoplasms and acute leukemia. Blood 2016, 127, 2391-2405. [CrossRef] [PubMed]

12. Carter, M.C.; Clayton, S.T.; Komarow, H.D.; Brittain, E.H.; Scott, L.M.; Cantave, D.; Gaskins, D.M.; Maric, I.; Metcalfe, D.D. Assessment of clinical findings, tryptase levels, and bone marrow histopathology in the management of pediatric mastocytosis. $J$. Allergy Clin. Immunol. 2015, 136, 1673-1679. [CrossRef]

13. Carter, M.C.; Bai, Y.; Ruiz-Esteves, K.N.; Scott, L.M.; Cantave, D.; Bolan, H.; Eisch, R.; Sun, X.; Hahn, J.; Maric, I.; et al. Detection of KIT D816V in peripheral blood of children with manifestations of cutaneous mastocytosis suggests systemic disease. $\mathrm{Br}$. J. Haematol. 2018, 183, 775-782. [CrossRef]

14. Alvarez-Twose, I.; Vañó-Galván, S.; Sánchez-Muñoz, L.; Morgado, J.M.; Matito, A.; Torrelo, A.; Jaén, P.; Schwartz, L.B.; Orfao, A.; Escribano, L. Increased serum baseline tryptase levels and extensive skin involvement are predictors for the severity of mast cell activation episodes in children with mastocytosis. Allergy 2012, 67, 813-818. [CrossRef]

15. Barnes, M.; Van, L.; DeLong, L.; Lawley, L.P. Severity of cutaneous findings predict the presence of systemic symptoms in pediatric maculopapular cutaneous mastocytosis. Pediatr. Dermatol. 2014, 31, 271-275. [CrossRef] [PubMed]

16. Brockow, K.; Ring, J.; Alvarez-Twose, I.; Orfao, A.; Escribano, L. Extensive blistering is a predictor for severe complications in children with mastocytosis. Allergy 2012, 67, 1323-1324. [CrossRef]

17. Valent, P. Mast cells, masters, and mastocytosis: Development of research since the times of Paul Ehrlich. Wiener Klinische Wochenschrift. 2004, 116, 645-646. [CrossRef] [PubMed]

18. Bezzerri, V.; Borgatti, M.; Finotti, A.; Tamanini, A.; Gambari, R.; Cabrini, G. Mapping the transcriptional machinery of the IL-8 gene in human bronchial epithelial cells. J. Immunol. 2011, 187, 6069-6081. [CrossRef] [PubMed]

19. Dispenza, M.C. Classification of hypersensitivity reactions. Allergy Asthma Proc. 2019, 40, 470-473. [CrossRef]

20. Simons, F.E.R.; Ebisawa, M.; Sanchez-Borges, M.; Thong, B.Y.; Worm, M.; Tanno, L.K.; Lockey, R.F.; El-Gamal, Y.M.; Brown, S.G.; Park, H.-S.; et al. 2015 update of the evidence base: World Allergy Organization anaphylaxis guidelines. World Allergy Organ. J. 2015, 8, 32. [CrossRef]

21. Greenhawt, M.; Akin, C. Mastocytosis and allergy. Curr. Opin. Allergy Clin. Immunol. 2007, 7, 387-392. [CrossRef] [PubMed]

22. Baghestanian, M.; Hofbauer, R.; Kiener, H.P.; Bankl, H.C.; Wimazal, F.; Willheim, M.; Scheiner, O.; Füreder, W.; Müller, M.R.; Bevec, D.; et al. The c-kit ligand stem cell factor and anti-IgE promote expression of monocyte chemoattractant protein-1 in human lung mast cells. Blood 1997, 90, 4438-4449. [CrossRef]

23. Wimazal, F.; Jordan, J.H.; Sperr, W.R.; Chott, A.; Dabbass, S.; Lechner, K.; Horny, H.P.; Valent, P. Increased angiogenesis in the bone marrow of patients with systemic mastocytosis. Am. J. Pathol. 2002, 160, 1639-1645. [CrossRef]

24. Hoermann, G.; Cerny-Reiterer, S.; Perné, A.; Klauser, M.; Hoetzenecker, K.; Klein, K.; Müllauer, L.; Gröger, M.; Nijman, S.M.; Klepetko, W.; et al. Identification of oncostatin M as a STAT5-dependent mediator of bone marrow remodeling in KIT D816Vpositive systemic mastocytosis. Am. J. Pathol. 2011, 178, 2344-2356. [CrossRef]

25. Greiner, G.; Witzeneder, N.; Berger, A.; Schmetterer, K.; Eisenwort, G.; Schiefer, A.I.; Roos, S.; Popow-Kraupp, T.; Müllauer, L.; Zuber, J.; et al. CCL2 is a KIT D816V-dependent modulator of the bone marrow microenvironment in systemic mastocytosis. Blood 2017, 129, 371-382. [CrossRef]

26. Collington, S.J.; Williams, T.J.; Weller, C.L. Mechanisms underlying the localisation of mast cells in tissues. Trends Immunol. 2011, 32, 478-485. [CrossRef] [PubMed]

27. Ravanbakhsh, N.; Kesavan, A. The role of mast cells in pediatric gastrointestinal disease. Ann. Gastroenterol. 2019, 32, 338-345. [CrossRef] [PubMed]

28. Klein, N.J.; Misseldine, S. Anesthetic considerations in pediatric mastocytosis: A review. J. Anesth. 2013, 27, 588-598. [CrossRef]

29. Castells, M.; Butterfield, J. Mast cell activation syndrome and mastocytosis: Initial treatment options and long-term management. J. Allergy Clin. Immunol Pract. 2019, 7, 1097-1106. [CrossRef]

30. Wodnar-Filipowicz, A.; Heusser, C.H.; Moroni, C. Production of the haemopoietic growth factors GM-CSF and interleukin-3 by mast cells in response to IgE receptor-mediated activation. Nature 1989, 339, 150-152. [CrossRef]

31. Echtenacher, B.; Männel, D.N.; Hültner, L. Critical protective role of mast cells in a model of acute septic peritonitis. Nature 1996, 381, 75-77. [CrossRef]

32. Malaviya, R.; Ikeda, T.; Ross, E.; Abraham, S.N. Mast cell modulation of neutrophil influx and bacterial clearance at sites of infection through TNF-alpha. Nature 1996, 381, 77-80. [CrossRef] [PubMed]

33. Gordon, J.R.; Galli, S.J. Mast cells as a source of both preformed and immunologically inducible TNF-alpha/cachectin. Nature 1990, 346, 274-276. [CrossRef] [PubMed] 
34. Matito, A.; Carter, M. Cutaneous and Systemic Mastocytosis in Children: A Risk Factor for Anaphylaxis? Curr. Allergy Asthma Rep. 2015, 15, 22. [CrossRef] [PubMed]

35. Wagner, N.; Staubach, P. Mastocytosis-Pathogenesis, clinical manifestation and treatment. JDDG 2018, 16, 42-57. [CrossRef]

36. Lange, M.; Niedoszytko, M.; Renke, J.; Glen, J.; Nedoszytko, B. Clinical aspects of paediatric mastocytosis: A review of 101 cases. J. Eur. Acad Dermatol. Venereol. 2013, 27, 97-102. [CrossRef]

37. Klaiber, N.; Kumar, S.; Irani, A.M. Mastocytosis in Children. Curr. Allergy Asthma Rep. 2017, 17, 80. [CrossRef]

38. Matito, A.; Azaña, J.M.; Torrelo, A.; Alvarez-Twose, I. Cutaneous Mastocytosis in Adults and Children: New Classification and Prognostic Factors. Immunol. Allergy Clin. N. Am. 2018, 38, 351-363. [CrossRef]

39. Lange, M.; Zawadzka, A.; Schrors, S.; Slomka, J.; Lugowska-Umer, H.; Nedoszytko, B.; Nowicki, R. The role of serum tryptase in the diagnosis and monitoring of pediatric mastocytosis: A single-center experience. Postepy Dermatol. Alergol. 2017, 34, 306-312. [CrossRef]

40. Heide, R.; Beishuizen, A.; De Groot, H.; Den Hollander, J.C.; Van Doormaal, J.J.; De Monchy, J.G.R.; Pasmans, S.; Van Gysel, D.; Oranje, A. Dutch National Mastocytosis Work Group Mastocytosis in children: A protocol for management. Pediatr. Dermatol. 2008, 25, 493-500. [CrossRef]

41. Theoharides, T.C. Autism spectrum disorders and mastocytosis. Int. J. Immunopathol. Pharmacol. 2009, 22, 859-865. [CrossRef]

42. Lange, M.; Niedoszytko, M.; Nedoszytko, B.; Łata, J.; Trzeciak, M.; Biernat, W. Diffuse cutaneus mastocytosis: Analysis of 10 cases and a brief review of the literature. J. Eur. Acad Dermatol. Venereol. 2012, 26, 1565-1571. [PubMed]

43. Brockow, K.; Jofer, C.; Behrendt, H.; Ring, J. Anaphylaxis in patients with mastocytosis: A study on history, clinical features and risk factors in 120 patients. Allergy 2008, 63, 226-232. [CrossRef] [PubMed]

44. Heinze, A.; Kuemmet, T.J.; Chiu, Y.E.; Galbraith, S.S. Longitudinal Study of Pediatric Urticaria Pigmentosa. Pediatr. Dermatol. 2017, 34, 144-149. [CrossRef]

45. Lieberman, P.; Camargo, C.A., Jr.; Bohlke, K.; Jick, H.; Miller, R.L.; Sheikh, A.; Simons, F.E. Epidemiology of anaphylaxis: Findings of the American College of Allergy, Asthma and Immunology Epidemiology of Anaphylaxis Working Group. Ann. Allergy Asthma Immunol. 2006, 97, 596-602. [CrossRef]

46. Gonzalez de Olano, D.; de la Hoz Caballer, B.; Nunez Lopez, R.; Sanchez Munoz, L.; Cuevas Agustin, M.; Dieguez, M.C.; Alvarez Twose, I.; Castells, M.C.; Escribano Mora, L. Prevalence of allergy and anaphylactic symptoms in 210 adult and pediatric patients with mastocytosis in Spain: A study of the Spanish network on mastocytosis (REMA). Clin. Exp. Allergy 2007, 37, 1547-1555. [CrossRef] [PubMed]

47. Matito, A.; Morgado, J.M.; Sánchez-López, P.; Álvarez-Twose, I.; Sánchez-Muñoz, L.; Orfao, A.; Escribano, L. Management of Anesthesia in Adult and Pediatric Mastocytosis: A Study of the Spanish Network on Mastocytosis (REMA) Based on 726 Anesthetic Procedures. Int. Arch. Allergy Immunol. 2015, 167, 47-56. [CrossRef]

48. Bonadonna, P.; Perbellini, O.; Passalacqua, G.; Caruso, B.; Colarossi, S.; Dal Fior, D.; Castellani, L.; Bonetto, C.; Frattini, F.; Dama, A.; et al. Clonal mast cell disorders in patients with systemic reactions to Hymenoptera stings and increased serum tryptase levels. J. Allergy Clin. Immunol. 2009, 123, 680-686. [CrossRef] [PubMed]

49. Niedoszytko, M.; de Monchy, J.; van Doormaal, J.J.; Jassem, E.; Oude Elberink, J.N. Mastocytosis and insect venom allergy: Diagnosis, safety and efficacy of venom immunotherapy. Allergy 2009, 64, 1237-1245. [CrossRef]

50. Brockow, K.; Akin, C. Hymenoptera-induced anaphylaxis: Is it a mast cell driven hematological disorder? Curr. Opin. Allergy Clin. Immunol. 2017, 17, 356-362. [CrossRef]

51. Oropeza, A.R.; Bindslev-Jensen, C.; Broesby-Olsen, S.; Kristensen, T.; Moller, M.B.; Vestergaard, H.; Kjaer, H.F.; Halken, S.; Lassen, A.; Mortz, C.G. Patterns of anaphylaxis after diagnostic work-up: A follow-up study of 226 patients with suspected anaphylaxis. Allergy 2017, 72, 1944-1952. [CrossRef]

52. Jarkvist, J.; Brockow, K.; Gulen, T. Low Frequency of IgE-Mediated Food Hypersensitivity in Mastocytosis. J. Allergy Clin. Immunol. Pract. 2020, 8, 3093-3101. [CrossRef]

53. Brockow, K.; Bonadonna, P. Drug allergy in mast cell disease. Curr. Opin. Allergy Clin. Immunol. 2012, 12, 354-360. [CrossRef] [PubMed]

54. Carter, M.C.; Metcalfe, D.D.; Matito, A.; Escribano, L.; Butterfield, J.H.; Schwartz, L.B.; Bonadonna, P.; Zanotti, R.; Triggiani, M.; Castells, M.; et al. Adverse reactions to drugs and biologics in patients with clonal mast cell disorders: A group report of the Mast Cells Disorder Committee, American Academy of Allergy and Immunology. J. Allergy Clin. Immunol. 2019, 143, 880-893. [CrossRef] [PubMed]

55. Parente, R.; Pucino, V.; Magliacane, D.; Petraroli, A.; Loffredo, S.; Marone, G.; Triggiani, M. Evaluation of vaccination safety in children with mastocytosis. Pediatr. Allergy Immunol. 2017, 28, 93-95. [CrossRef] [PubMed]

56. Zanoni, G.; Zanotti, R.; Schena, D.; Sabbadini, C.; Opri, R.; Bonadonna, P. Vaccination management in children and adults with mastocytosis. Clin. Exp. Allergy 2017, 47, 593-596. [CrossRef] [PubMed]

57. Carter, M.C.; Uzzaman, A.; Scott, L.M.; Metcalfe, D.D.; Quezado, Z. Pediatric mastocytosis: Routine anesthetic management for a complex disease. Anesth Analg 2008, 107, 422-427. [CrossRef]

58. Akin, C.; Scott, L.M.; Kocabas, C.N.; Kushnir-Sukhov, N.; Brittain, E.; Noel, P.; Metcalfe, D.D. Demonstration of an aberrant mast-cell population with clonal markers in a subset of patients with "idiopathic" anaphylaxis. Blood 2007, 110, 2331-2333. [CrossRef] [PubMed] 
59. Shaffer, H.C.; Parsons, D.J.; Peden, D.B.; Morrell, D. Recurrent syncope and anaphylaxis as presentation of systemic mastocytosis in a pediatric patient: Case report and literature review. J. Am. Acad Dermatol. 2006, 54, 210-213. [CrossRef]

60. Brockow, K. Epidemiology, prognosis, and risk factors in mastocytosis. Immunol. Allergy Clin. North. Am. 2014, 34, 283-295. [CrossRef]

61. Schuch, A.; Brockow, K. Mastocytosis and Anaphylaxis. Immunol. Allergy Clin. North. Am. 2017, 37, 153-164. [CrossRef]

62. O'Connell, M.P.; Lyons, J.J. Hymenoptera venom-induced anaphylaxis and hereditary alpha-tryptasemia. Curr. Opin. Allergy Clin. Immunol. 2020, 20, 431-437. [CrossRef] [PubMed]

63. Robey, R.C.; Wilcock, A.; Bonin, H.; Beaman, G.; Myers, B.; Grattan, C.; Briggs, T.A.; Arkwright, P.D. Hereditary AlphaTryptasemia: UK Prevalence and Variability in Disease Expression. J. Allergy Clin. Immunol. Pract. 2020, 8, 3549-3556. [CrossRef]

64. Lyons, J.J. Hereditary Alpha Tryptasemia: Genotyping and Associated Clinical features. Immunol. Allergy Clin. North. Am. 2018, 63, 483-495. [CrossRef]

65. Greiner, G.; Sprinzl, B.; Górska, A.; Ratzinger, F.; Gurbisz, M.; Witzeneder, N.; Schmetterer, K.G.; Gisslinger, B.; Uyanik, G.; Hadzijusufovic, E.; et al. Hereditary alpha tryptasemia is a valid genetic biomarker for severe mediator-related symptoms in mastocytosis. Blood 2020, 10, 2020006157. [CrossRef] [PubMed]

66. Le, Q.T.; Lyons, J.J.; Naranjo, A.N.; Olivera, A.; Lazarus, R.A.; Metcalfe, D.D.; Milner, J.D.; Schwartz, L.B. Impact of naturally forming human $\alpha / \beta$-tryptase heterotetramers in the pathogenesis of hereditary $\alpha$-tryptasemia. J. Exp. Med. 2019, 216, $2348-2361$. [CrossRef] [PubMed]

67. Lyons, J.J.; Chovanec, J.; O'Connell, M.P.; Liu, Y.; Šelb, J.; Zanotti, R.; Bai, Y.; Kim, J.; Le, Q.T.; DiMaggio, T.; et al. Heritable risk for severe anaphylaxis associated with increased $\alpha$-tryptase-encoding germline copy number at TPSAB. J. Allergy Clin. Immunol. 2021, 147, 622-632. [CrossRef] [PubMed]

68. Sabato, V.; Van De Vijver, E.; Hagendorens, M.; Vrelust, I.; Reyniers, E.; Fransen, E.; Bridts, C.; De Clerck, L.; Mortier, G.; Valent, P.; et al. Familial hypertryptasemia with associated mast cell activation syndrome. J. Allergy Clin. Immunol. 2014, 134, 1448-1450.e3. [CrossRef] [PubMed]

69. Sznurkowska, K.; Plata- Nazar, K.; Sikorska-Wiśniewska, G.; Gruszczyńska, I.; Renke, J.; Niedoszytko, M.; Gleń, J.; Kamińska, B. Serum Concentrations of Tryptase in Children. Pediatric. Allergy Immunol. Pulmonol. 2014, 27, 70-74. [CrossRef]

70. Valent, P.; Escribano, L.; Broesby-Olsen, S.; Hartmann, K.; Grattan, C.; Brockow, K.; Niedoszytko, M.; Nedoszytko, B.; Oude Elberink, J.N.; Kristensen, T.; et al. Proposed diagnostic algorithm for patients with suspected mastocytosis: A proposal of the European Competence Network on Mastocytosis. Allergy 2014, 69, 1267-1274. [CrossRef]

71. Horny, H.P.; Akin, C.; Arber, D.; Peterson, L.A.; Tefferi, A.; Metcalfe, D.D.; Bennett, J.M.; Bain, B.; Escribano, L.; Valent, P. Mastocytosis. In WHO Classification of Tumours of Haematopoietic and Lymphoid Tissues; Swerdlow, S.H., Campo, E., Harris, N.L., Jaffe, E.S., Pileri, S.A., Stein, H., Thiele, J., Arber, D.A., Hasserjian, R.P., Le Beau, M.M., et al., Eds.; IARC Press: Lyon, France, 2017; pp. 62-69.

72. Valent, P.; Akin, C.; Escribano, L.; Födinger, M.; Hartmann, K.; Brockow, K.; Castells, M.; Sperr, W.R.; Kluin-Nelemans, H.C.; Hamdy, N.A.; et al. Standards and standardization in mastocytosis: Consensus statements on diagnostics, treatment recommendations and response criteria. Eur. J. Clin. Investig. 2007, 37, 435-553. [CrossRef]

73. Valent, P.; Akin, C.; Arock, M.; Brockow, K.; Butterfield, J.H.; Carter, M.C.; Castells, M.; Escribano, L.; Hartmann, K.; Lieberman, P.; et al. Definitions, criteria and global classification of mast cell disorders with special reference to mast cell activation syndromes: A consensus proposal. Int. Arch. Allergy Immunol. 2012, 157, 215-225. [CrossRef]

74. Brockow, K.; Akin, C.; Huber, M.; Metcalfe, D. Assessment of the extent of cutaneous involvement in children and adults with mastocytosis: Relationship to symptomatology, tryptase levels, and bone marrow pathology. J. Am. Acad Dermatol. 2003, 48, 508-516. [CrossRef] [PubMed]

75. Czarny, J.; Żuk, M.; Żawrocki, A.; Plata-Nazar, K.; Biernat, W.; Niedoszytko, M.; Ługowska-Umer, H.; Nedoszytko, B.; Wasag, B.; Nowicki, R.J.; et al. New Approach to Paediatric Mastocytosis: Implications of KIT D816V Mutation Detection in Peripheral Blood. Acta Derm Venereol. 2020, 100, adv00149. [CrossRef]

76. Broesby-Olsen, S.; Carter, M.; Kjaer, H.F.; Mortz, C.G.; Møller, M.B.; Kristensen, T.K.; Bindslev-Jensen, C.; Agertoft, L. Pediatric Expression of Mast Cell Activation Disorders. Immunol. Allergy Clin. N. Am. 2018, 38, 365-377. [CrossRef] [PubMed]

77. Azana, J.M.; Torrelo, A.; Matito, A. Update on mastocytosis (part 2): Categories, Prognosis, and Treatment. Actas Derm. 2016, 107, $15-22$.

78. Edwards, A.M.; Hagberg, H. Oral and inhaled sodium cromoglicate in the management of systemic mastocytosis: A case report. J. Med. Case Rep. 2010, 4, 193. [CrossRef]

79. Jenkinson, H.A.; Lundgren, A.D.; Carter, M.C.; Diaz, L.Z.; Levy, M.L. Management of neonate with diffuse cutaneous mastocytosis: Case report and literature review. Pediatric. Dermatol. 2019, 36, 486-489. [CrossRef]

80. Leung, A.K.C.; Lam, J.M.; Leong, K.F. Childhood Solitary Cutaneous Mastocytoma: Clinical Manifestations, Diagnosis, Evaluation, and Management. Curr. Pediatr. Rev. 2019, 15, 42-46. [CrossRef]

81. Patrizi, A.; Tabanelli, M.; Neri, I.; Virdi, A. Topical corticosteroids versus "wait and see" in the management of solitary mastocytoma in pediatric patients: A long-term follow-up. Dermatol. Ther. 2015, 28, 57-61. [CrossRef] [PubMed]

82. Mashiah, J.; Harel, A.; Bodemer, C.; Hadj-Rabia, S.; Goldberg, I.; Sprecher, E.; Kutz, A. Topical pimecrolimus for pediatric cutaneous mastocytosis. Clin. Exp. Dermatol. 2018, 43, 559-565. [CrossRef] 
83. Correia, O.; Duarte, A.; Quirino, P.; Azevedo, R.; Delgado, L. Cutaneous mastocytosis: Two pediatric cases treated with topical pimecrolimus. Dermatol. Online J. 2010, 16, 8. [PubMed]

84. Brazzelli, V.; Grassi, S.; Merante, S.; Grasso, V.; Ciccocioppo, R.; Bossi, G.; Borroni, G. Narrow-band UVB phototherapy and psoralen-ultraviolet A photochemotherapy in the treatment of cutaneous mastocytosis: A study in 20 pateints. Photodermatol. Photoimmunol. Photomed. 2016, 32, 238-246. [CrossRef]

85. Kinsler, V.A.; Hawk, J.L.M.; Atherton, D.J. Diffuse cutaneous mastocytosis treated with psoralen photochemtherapy: Case report and review of literature. Br. J. Dermatol. 2005, 152, 179-180.

86. Siebenhaar, F.; Akin, C.; Bindslev-Jensen, C.; Maurer, M.; Broesby-Olsen, S. Treatment strategies in mastocytosis. Immunol. Allergy Clin. North. Am. 2014, 34, 433-447. [CrossRef] [PubMed]

87. Eustace, K.; Dolman, S.; Alsharqi, A.; Sharpe, G.; Parslew, R. Use of Phototherapy in Children. Pediatric. Dermatol. 2017, 34, 150-155. [CrossRef] [PubMed]

88. Hosking, A.M.; Makdisi, J.; Ortenzio, F.; de Feraudy, S.; Smith, J.; Linden, K. Diffuse cutaneous mastocytosis: Case report and literature review. Pediatr. Dermatol. 2018, 35, e348-e352. [CrossRef]

89. Frieri, M.; Quershi, M. Pediatric Mastocytosis: A Review of the Literature. Pediatr. Allergy Immunol. Pulmonol. 2013, 26, 175-180. [CrossRef]

90. Nurmatov, U.B.; Rhatigan, E.; Simons, F.E.R.; Sheikh, A. $\mathrm{H}_{1}$-antihistamines for primary mast cell activation syndromes: A systematic review. Allergy 2015, 70, 1052-1061. [CrossRef]

91. Shin, J.M.; Vagin, O.; Munson, K.; Kidd, M.; Modlin, I.M.; Sachs, G. Molecular mechanisms in therapy of acid-related diseases. Cell. Mol. Life Sci. 2008, 65, 264-281. [CrossRef] [PubMed]

92. Ring, J.; Beyer, K.; Biedermann, T.; Bircher, A.; Duda, D.; Fischer, J.; Friedrichs, F.; Fuchs, T.; Gieler, U.; Jakob, T.; et al. Guideline for acute therapy and management of anaphylaxis: S2 Guideline of the German Society for Allergology and Clinical Immunology (DGAKI), the Association of German Allergologists (AeDA), the Society of Pediatric Allergy and Environmental Medicine (GPA), the German Academy of Allergology and Environmental Medicine (DAAU), the German Professional Association of Pediatricians (BVKJ), the Austrian Society for Allergology and Immunology (OGAI), the Swiss Society for Allergy and Immunology (SGAI), the German Society of Anaesthesiology and Intensive Care Medicine (DGAI), the German Society of Pharmacology (DGP), the German Society for Psychosomatic Medicine (DGPM), the German Working Group of Anaphylaxis Training and Education (AGATE) and the patient organization German Allergy and Asthma Association (DAAB). Allergo J. Int. 2014, 23, 96-112. [PubMed]

93. Brockow, K.; Schallmayer, S.; Beyer, K.; Biedermann, T.; Fischer, J.; Gebert, N.; Grosber, M.; Jakob, T.; Klimek, L.; Kugler, C.; et al. Effects of a structured educational intervention on knowledge and emergency management in patients at risk for anaphylaxis. Allergy 2015, 70, 227-235. [CrossRef]

94. Le, M.; Miedzybrodzki, B.; Olynych, T.; Chapdelaine, H.; Ben-Shoshan, M. Natural history and treatment of cutaneous and systemic mastocytosis. Postgrad Med. 2017, 129, 896-901. [CrossRef]

95. Slapnicar, C.; Trinkaus, M.; Lisa Hicks, L.; Vadas, P. Efficacy of Omalizumab in Indolent Systemic Mastocytosis. Case Rep. Hematol. 2019, 16, 3787586. [CrossRef]

96. Hinojosa, T.; Lewis, D.J.; Vangipuram, R.; Safeer, L.; Mui, U.N.; Haley, C.; Konoplev, S.; Tyring, S.K. The efficacy of omalizumab in Cutaneous Mastocytosis: A case series. Dermatol. Ther. 2019, 32, e12848. [CrossRef]

97. Matito, A.; Blázquez-Goñi, C.; Morgado, J.M.; Álvarez-Twose, I.; Mollejo, M.; Sánchez-Muñoz, L.; Escribano, L. Short-term omalizumab treatment in an adolescent with cutaneous mastocytosis. Ann. Allergy Asthma Immunol. 2013, 111, 425-426. [CrossRef] [PubMed]

98. Hughes, J.D.M.; Olynyc, T.; Chapdelaine, H.; Segal, L.; Miedzybrodzki, B.; Ben-Shoshan, M. Effective management of severe cutaneous mastocytosis in young children with omalizumab (Xolair ${ }^{\circledR}$ ). Clin. Exp. Dermatol. 2018, 43, 573-576. [CrossRef]

99. Broesby-Olsen, S.; Vestergaard, H.; Mortz, C.G.; Jensen, B.; Havelund, T.; Hermann, A.P.; Siebenhaar, F.; Møller, M.B.; Kristensen, T.K.; Bindslev-Jensen, C. Mastocytosis Centre Odense University Hospital (MastOUH). Omalizumab prevents anaphylaxis and improves symptoms in systemic mastocytosis: Efficacy and safety observations. Allergy 2018, 73, 230-238. [CrossRef] [PubMed]

100. Jendoubi, F.; Gaudenzio, N.; Gallini, A.; Negretto, M.; Paul, C.; Bulai Livideanu, C. Omalizumab in the treatment of adult patients with mastocytosis: A systematic review. Clin. Exp. Allergy 2020, 50, 654-661. [CrossRef]

101. Bell, M.C.; Jackson, D.J. Prevention of anaphylaxis related to mast cell activation syndrome with omalizumab. Ann. Allergy Asthma Immunol. 2012, 108, 383-384. [CrossRef]

102. Constantine, G.M.; Bressler, P.B.; Petroni, D.; Metcalfe, D.D.; Carter, M.C. Twelve-year follow-up of omalizumab therapy for anaphylaxis in 2 patients with systemic mastocytosis. J. Allergy Clin. Immunol. Pract. 2019, 7, 1314-1316. [CrossRef] [PubMed]

103. Distler, M.; Maul, J.T.; Steiner, U.C.; Jandus, P.; Kolios, A.G.A.; Murer, C.; Graf, N.; Seebach, J.D.; Pichler, W.J.; Navarini, A.A.; et al. Efficacy of omalizumab in mastocytosis: Allusive indication obtained from a prospective, double-blind, multicenter study (XOLIMA study). Dermatology 2020, 20, 1-11. [CrossRef] [PubMed]

104. Lemal, R.; Fouquet, G.; Terriou, L.; Vaes, M.; Livideanu, C.B.; Frenzel, L.; Barete, S.; Canioni, D.; Lhermitte, L.; Rossignol, J.; et al. Omalizumab Therapy for Mast Cell-Mediator Symptoms in Patients with ISM, CM, MMAS, and MCAS. J. Allergy Clin. Immunol. Pract. 2019, 7, 2387-2395.e3. [CrossRef] [PubMed]

105. Kaplan, A.P.; Giménez-Arnau, A.M.; Saini, S.S. Mechanisms of action that contribute to efficacy of omalizumab in chronic spontaneous urticaria. Allergy 2017, 72, 519-533. [CrossRef] 